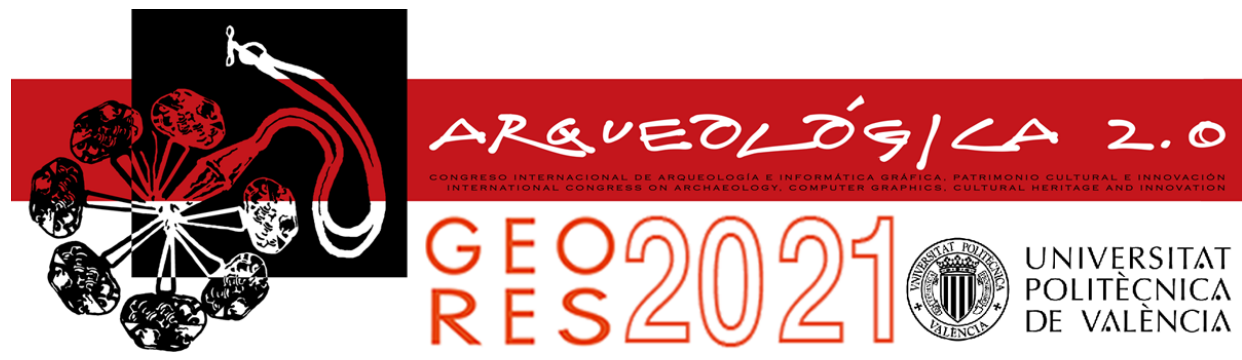

Proceedings of the joint international event $9^{\text {th }}$ ARQUEOLÓGICA

$2.0 \& 3^{\text {rd }}$ GEORES

Valencia (Spain).

26-28 April 2021

\title{
THE ETRUSCAN CITY GATES OF PERUGIA: GEOMATIC TECHNIQUES FOR THE DOCUMENTATION AND STUDY OF AN URBAN HISTORY HERITAGE
}

\author{
Fabio Radicionia, ${ }^{*}$, Pietro Matracchi ${ }^{b}$, Aurelio Stoppinia ${ }^{a}$, Grazia Tosia $^{\mathrm{a}}$, Laura Marconi ${ }^{\mathrm{a}}$ \\ a Department of Engineering, University of Perugia, Via G. Duranti 93, 06125 Perugia, Italy. fabio.radicioni@unipg.it; \\ aurelio.stoppini@unipg.it; grazia.tosi@unipg.it; laura.marconi@collaboratori.unipg.it \\ b Department of Architecture, University of Firenze, Via della Mattonaia 8, 50121 Firenze, Italy. pietro.matracchi@unifi.it
}

\begin{abstract}
:
The Engineering Department of the University of Perugia and the Architecture Department of the University of Florence have started a research project on the ancient city gates of Perugia, belonging to the Etruscan city, dating between the third and second centuries B.C., and to the subsequent city wall completed in the twelfth century. In this paper, focus is placed on three Etruscan gates - Porta Eburnea (also called Porta della Mandorla), Porta Cornea and Porta Trasimena which have in common profound Middle Age transformations and further significant context changes following the loss of function as defensive walls. Due to the decommissioning of this urban infrastructure, the gates have assumed a marginal role; nowadays they are almost completely absorbed by residential buildings, almost losing the memory of their origins and of the important Etruscan remains that are still preserved in the gates. Geomatic surveys on the three Etruscan gates were carried out by the Geomatics Laboratory of Perugia University in the frame of a research project financed by the Cassa di Risparmio di Perugia Foundation. The survey was carried out by means of a coordinated use of more Geomatic techniques: GNSS, Total Station, Terrestrial LIDAR and Digital Photogrammetry. From LIDAR and photogrammetry were derived dense point clouds, beside CAD plans, sections and elevations. The information acquired with these detailed surveys provide a completely new and accurate documentary evidence of the gates' consistency, allowing to identify the actions and interventions that have changed their structure over time.
\end{abstract}

Keywords: cultural heritage, 3D reconstruction, laser scanning, digital photogrammetry, restoration, Etruscan walls

\section{Introduction}

The research project concerned the urban gates of Perugia, belonging to the first walls of the Etruscan city, which can be dated between the $3^{\text {rd }}$ and $2^{\text {nd }}$ centuries B.C., and the subsequent wall circle erected to protect the urban development of the medieval era and substantially completed in the $12^{\text {th }}$ century (Begni, 1956; Fiocca, 1918).

In this paper, the focus was placed on three Etruscan gates - Porta Eburnea or della Mandorla, Porta Cornea and Porta Trasimena - united by profound transformations from the Middle Ages and further incisive changes in context that followed the loss of the defensive function of the walls. The decommissioning of this urban infrastructure has placed the gates in a marginal role; today they are almost completely engulfed by residential buildings, making them almost lose the memory of the origins and the important Etruscan remains that are still preserved in them (Calderoni, 1977).

The studies on the gates to date have been limited to the observation of partial architectural aspects and considerations carried out on an urban scale that link the gates to the history of the city of Perugia (Bilancia 2015; Fiocca, 1926).

The purpose of this research is to document the gates with detailed surveys that highlight their architectural peculiarities and their state of conservation. In particular, the laser scanner surveys here presented have been carried out for the first time with such technique on the three gates. The Perugia gates are monumental and complex historical manufacts, characterized by a remarkable height compared to the narrow internal and external adjacent spaces.

The study of the gates presented in this paper, in addition to highlight the traces left by complex construction events, such as the inscriptions engraved in the reused ashlars, has deepened the knowledge on the further relevant transformations that the Etruscan structure of the Eburnea, Cornea and Trasimena gates have undergone over time.

The original remains, the reused materials, the vast medieval reconstructions and the still subsequent $19^{\text {th }}$

`Corresponding Author: Fabio Radicioni, fabio.radicioni@unipg.it 
century contributions of these architectural artefacts, have been identified, highlighting the effects of the subsequent restoration interventions.

For decades now, Geomatics, thanks to its increasingly advanced and powerful survey techniques, has played a fundamental role in the documentation of cultural heritage all over the world (Balletti, Costa, Guerra, Martinello, \& Vernier, 2018; Hatzopoulos et al., 2017; Radicioni et al., 2017; Tucci, Bonora, Fiorini, \& Conti, 2016; Grussenmeyer, Landes, Voegtle, \& Ringle, 2008).

The present survey on three Etruscan gates was performed by a coordinated integration of the following techniques of applied Geomatics:

- GNSS positioning, for a general georefencing of the gates and the surrounding areas and buildings in a global datum (the European datum ETRF2000);

- Three-dimensional (planimetric-altimetric) local networks measured with terrestrial methods, for the accurate georeferencing of targets (to be used for LIDAR point clouds registration) and architectural details of the manufacts;

- $\quad$ Terrestrial LIDAR, for the detailed survey and 3D reconstruction of all external surfaces and most of the internal spaces;

- Digital photogrammetry, for an integration and/or an alternative to the LIDAR survey.

From LIDAR and photogrammetry were derived dense point clouds, accurately describing the external and internal geometry of the manufacts. Data provided by the point clouds were then processed in order to obtain detailed plans, sections and elevations with CAD software.

The information acquired with these detailed surveys provide documentary evidence of the doors consistency for the first time, allowing identifying the actions and interventions that have changed their structure over time.

\section{The Etruscan Wall and its gates}

The first Etruscan urban settlement characterized by a strong urban connotation, dating back to the $8^{\text {th }}$ century B.C., is certified by an extended masonry now incorporated in the hypogeum spaces of the Capitular Museum of the Cathedral of San Lorenzo. It was an extensive embankment where the acropolis of Perugia developed.

The Etruscan city wall, dated between the third and the early $2^{\text {nd }}$ century B.C., developed for over $3 \mathrm{~km}$ on the edge of two hills, Colle Sole and Colle Landone, with a path that followed the slopes orography (Nicolini, 1986; Defosse, 1980). The city wall was built with square travertine blocks placed on fairly regular rows, dry-walled, without mortar (Giambi, 2004; Amorini, 1996).

The siege led by Octavian in the winter of $41-40$ B.C. caused the fall of the city and its consequent raid and damage. With the reconstruction, the city took the name of "Augusta Perusia" and the city power was entrusted to the most powerful family, the Vibi. In the $3^{\text {rd }}$ century B.C., Emperor Vibio Treboniano Gallo, born in Perugia, reigned from 251 to 253 B.C. (Cotana, 2012).
The study of the city gates, in addition to examining some traces left by these events, such as the inscriptions engraved in the ashlars, investigated the further significant transformations that the Etruscan layout of the gates underwent over time. The original remains, the materials reused, the extended medieval transformations and the still subsequent contributions (perhaps made by restorers) of these architectural artifacts, characterized by modest size but very complex in terms of the incurred modifications, have been identified (Fig. 1).

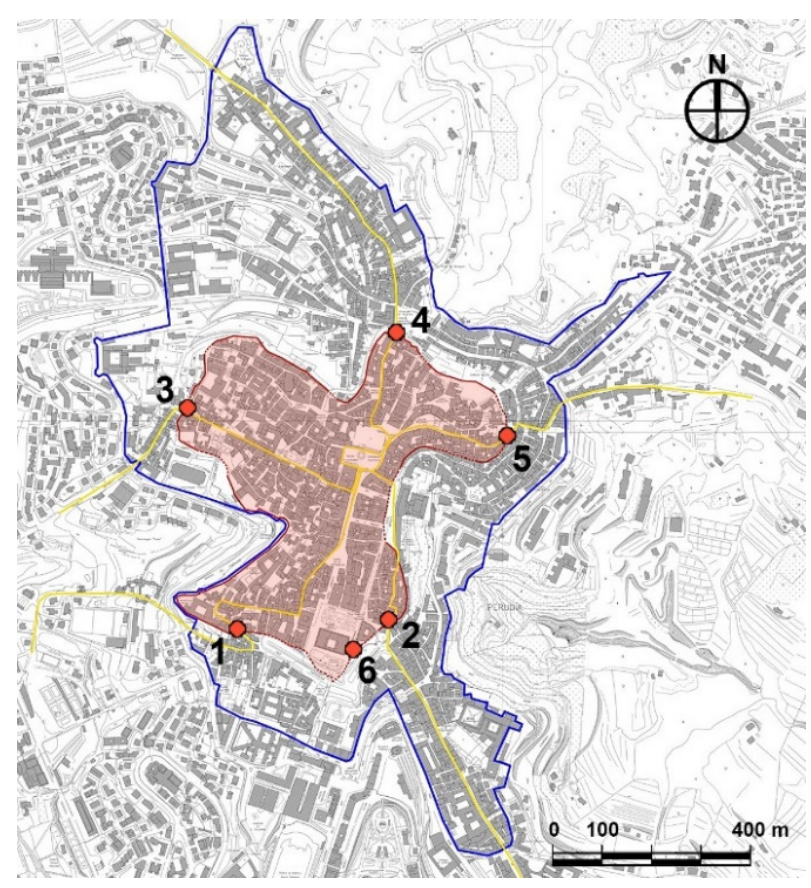

Figure 1: Map of Perugia city with the layout of the Etruscan and Medieval walls and collocation of their gates: 1. Porta Eburnea; 2. Porta Cornea; 3. Porta Trasimena; 4. Porta Augusta; 5. Arco dei Gigli; 6. Porta Marzia.

\subsection{Knowledge and interpretation}

The new surveys of the wall facings and the 3D models, which had never been realized before for these city gates, made possible an accurate analysis and study of their construction features. It was possible to highlight many relevant aspects and themes thanks to the particular technical characteristics of the survey, which combines an accurate three-dimensional description of the geometry with a high definition in the representation of the surface textures.

The materials, the state of conservation, the different stone workmanship, the way the rows were laid, the homogeneity and inconsistency in the masonry techniques were carefully identified. All these information highlighted aspects that can be attributed to various worksite practices. This led to the interpretation of the gates' current structure as a palimpsest of interventions from different periods.

The main phases identified concern the remains of the Etruscan walls and the medieval modifications, which were achieved in some cases with the reuse of Etruscan stone material. In more recent times, at the top of the walls some adaptations to everyday living have been made, e.g. by creating small terraces connected to the adjacent houses. Some portions of the walls, apparently belonging 
to the original structure, can be identified as restoration works.

\subsection{Porta Eburnea (or Arco della Mandorla)}

Porta Eburnea shows great part of the Etruscan walls on the side that corresponded to the outside of the city.

The masonry consists of large squared ashlars laid in continuous rows, from about 55 to $62 \mathrm{~cm}$ high. An additional wall parallel to the road that crosses the door is connected to the gate wall.

In the first section of this masonry, ashlars of similar size to those of the gate were used; in the following part, ashlars of lower height overlap forming a retaining wall. These walls are probably attributable to the Etruscan period. However, also due to the discontinuities that characterize the foundations, the retaining wall seems to be placed in a different construction phase.

The large ashlars facing in the vaulted gateway is interrupted to then be present again on the inner side of the city walls; the interrupted part corresponds to the internal corner of the gate which was subsequently rebuilt. Anyway, the remaining Etruscan wall on three sides outlines the original overall dimensions of the sidewalls of the gate.

A further important evidence shows on the most unaltered side of the Etruscan gate. In the highest part, the ashlars are set back from those below; they are interrupted in each row by tracing a curved line profile, which corresponded to the extrados of the original arch that adorned the side of the entrance to the city. Assuming the primitive arch was a semicircle, the remaining extrados curve would suggest a greater width Etruscan gate than the current one (Fig. 2).

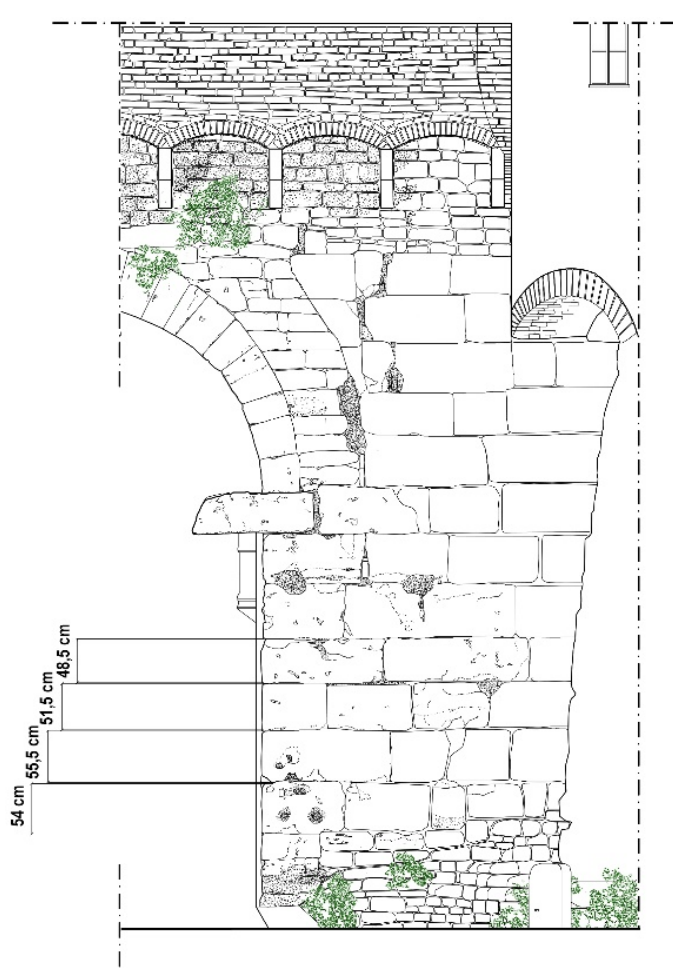

Figure 2: Detail of the gate side with the trace of the original arch and the size of the ashlars in different rows.
The present context does not explain the different state of conservation between the two Etruscan walls sides, of which the internal one is considerably worse (Fig. 3). This is probably due to particular conditions which existed in the past and which have changed over time.

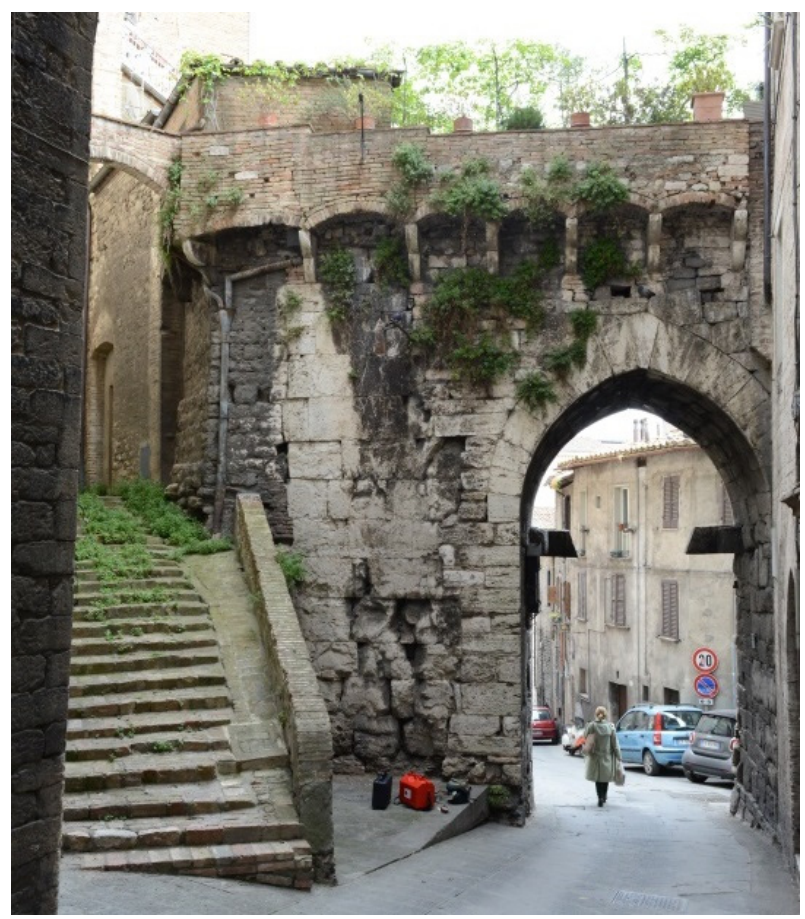

Figure 3: Porta Eburnea, internal side.

In the best-preserved parts, the facing shows a refined thin joints working. Sometimes the vertical joints have a slight incline, perhaps in order to obtain a jack arch effect helping to create connections between adjacent ashlars of the same row.

The inner side of the remaining gate abutment was completely absorbed by the expanded urban area, aligned today with the vaulted gateway.

The sides below the arch and outside the walls are all visible. In this case the masonry is heterogeneous, with variable-sized ashlars and discontinuous rows. On the external side in particular, the larger ashlars are in the lower part and near the gate arch; the remaining part is more homogeneous for the use of small ashlars on more regular courses.

Some of the larger ashlars are probably reused materials from the pre-existing Etruscan gate. This is particularly evidenced by the ashlars with engraved letters. "VIB" is engraved in an ashlar probably referring to the word "COLONIA VIBA". In an ashlar, an "S" engraving preceded by the trace of a further letter, probably a "U", would suggest letters belonging to one of the two words writing "AUGUSTA PERUSIA". These signs are recurring in the Etruscan wall gates, such as the Etruscan Arch or Porta Marzia (Gigliarelli, 2016; Marcaccioli, 2014).

The gate is also characterized by a Florentine pointed arch with two very protruding ashlars with diagonal termination at the external side impost, on which a further ashlar was to rest forming a jack arch lintel. Close to this lintel there is a stone hinge on each side, with a horizontal hook, in which the wooden doors that closed the gate could rotate, leaning on the architrave itself. 
The Etruscan period was then followed by a deep reconstruction during the Middle Ages, with a consequent reduction of the original gate width and the re-use of part of the travertine ashlars. The Etruscan remains of the Porta Eburnea and the exposed foundations of the Etruscan walls continuing outside on Via San Giacomo, would suggest that the Etruscan layout was maintained during the gate medieval reconstruction, but at the same time the Etruscan walking levels had to be lowered (Fig. 4).

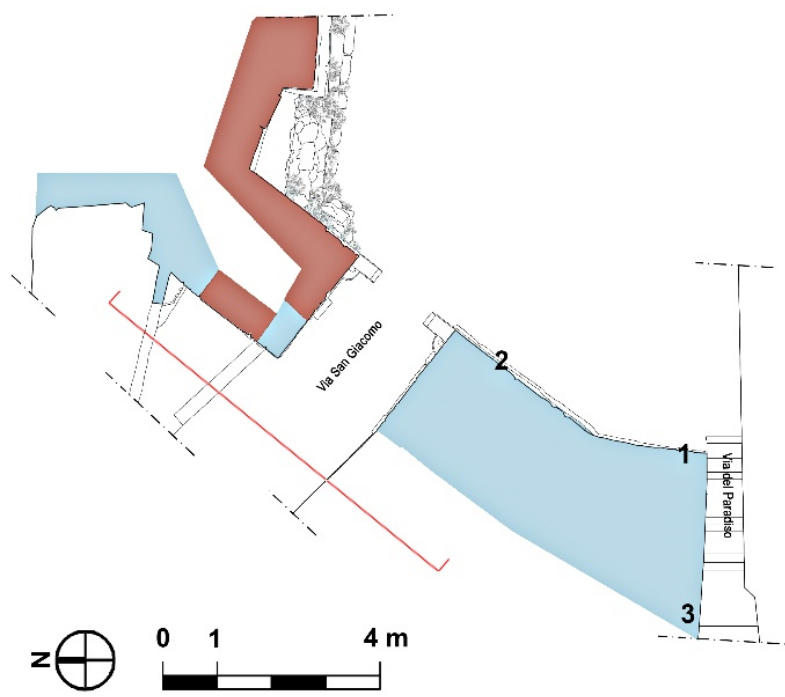

Figure 4: Plan of Porta Eburnea with the original Etruscan parts in red. 1, 2, 3 Etruscan ashlars with epigraphs reused during medieval period (light blue).

The gate corbelled crowning, with double quarter-circle stone corbel on which segmental arches and brick parapets rest, are to be considered a later intervention. The corbels are perhaps due to a restoration; while the construction of a connection or a terrace for private residential use on the gate crowning could still be later, as the final act of a long urban development process, almost completely absorbing the Porta Eburnea (Fig. 5).

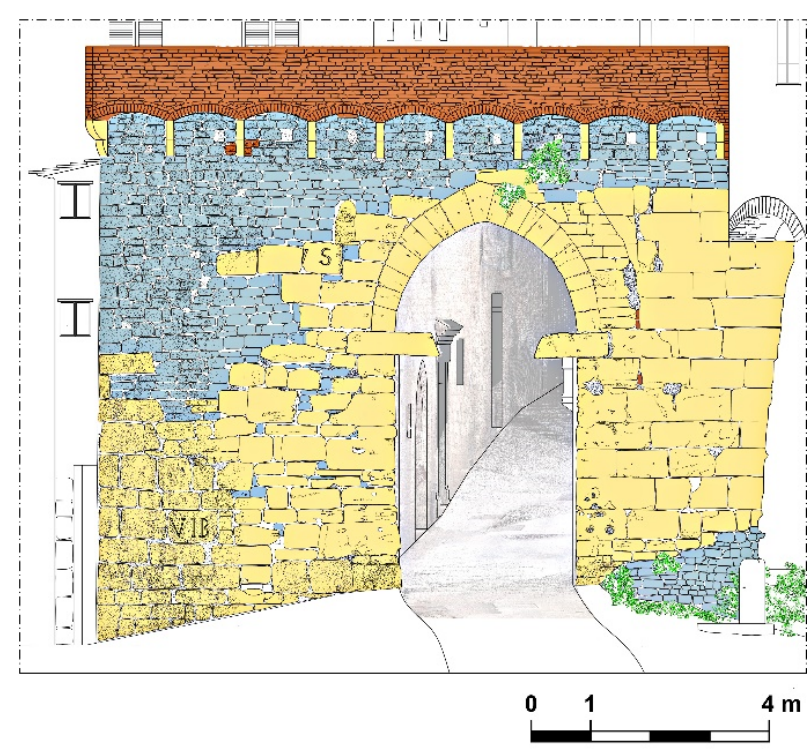

Figure 5: External front of the gate with highlighted the ashlars in travertine (yellow), limestone (blue) and the brick parts (red).

\subsection{Porta Cornea}

In via Sant'Ercolano, near the homonymous church, there is Porta Cornea, also known as Arco di Sant'Ercolano, Porta Berarda or Comitoli (Marcaccioli, 2015).

One abutment of the gate is almost completely incorporated by the progressive extension of the buildings; the side below the arch and a small section of the side towards Sant'Ercolano church are still visible. The other abutment of the gate emerges from the surrounding building for a short distance about 1 meter deep. On this same side, above the small building that leans against the external side of the gate, a portion of the walls with large travertine ashlars survives, dating back to the Etruscan period (Fig. 6).

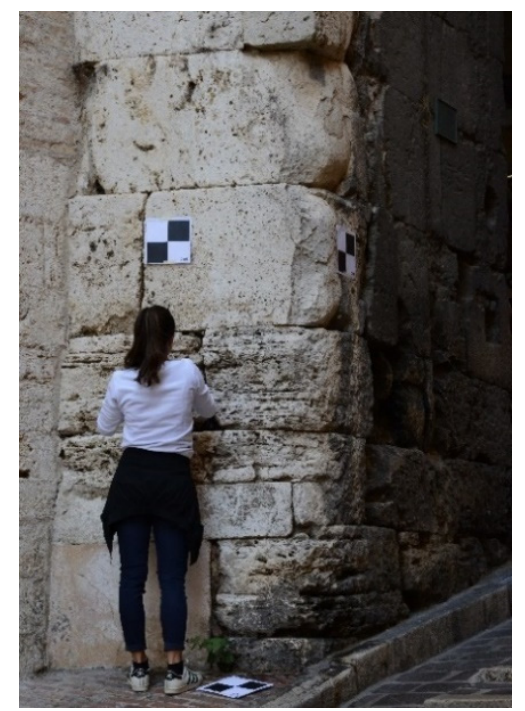

Figure 6: Porta Cornea, detail of the large ashlars.

This section of the wall shows a rotation with respect to the position of the gate. The abutment on the same side does not have a rectangular but slightly slanted plan. The gate opening has a mostly unvaried width.

However, the two sides of the gate differ in one important aspect. The almost completely incorporated abutment has the external side with an evident retaining wall profile in the upper part, created by the retreat of each row with respect to the one below. This feature is missing in the lower part due to the alterations related to the creation of ground floor access of the adjacent building (Fig. 7).

The other wall of the gate does not present this feature in an equally marked way; it has an apparently smooth profile, with undetectable projections between one row and another, but recorded by the laser scanner survey. However, both sides share the use of masonry with large well-squared travertine ashlars.

Considering that Porta Cornea has a width (about $3.40 \mathrm{~m}$ ) similar to that of Porta Eburnea (about $3.24 \mathrm{~m}$ ), it could be hypothesized that the abutment where the retaining wall is not noticed is a medieval reconstruction performed with Etruscan ashlars.

The medieval reconstruction with a gate opening narrower than the pre-existing Etruscan gate could be confirmed by a wall trace that can be observed on the internal side of the reconstructed abutment. Just above the arch shutter and close to the adjacent building, there 
are three ashlars with radial joints that could testify to the position of the primordial Etruscan arch. However, only a part of these ashlars is visible, which moreover is now covered by a thick black patina (Fig. 8). In order to define with certainty if they are actually residual ashlars of a preexisting arch or erratic pieces of reuse, it would be necessary to closely analyse these elements, possibly after having cleaned the surface.

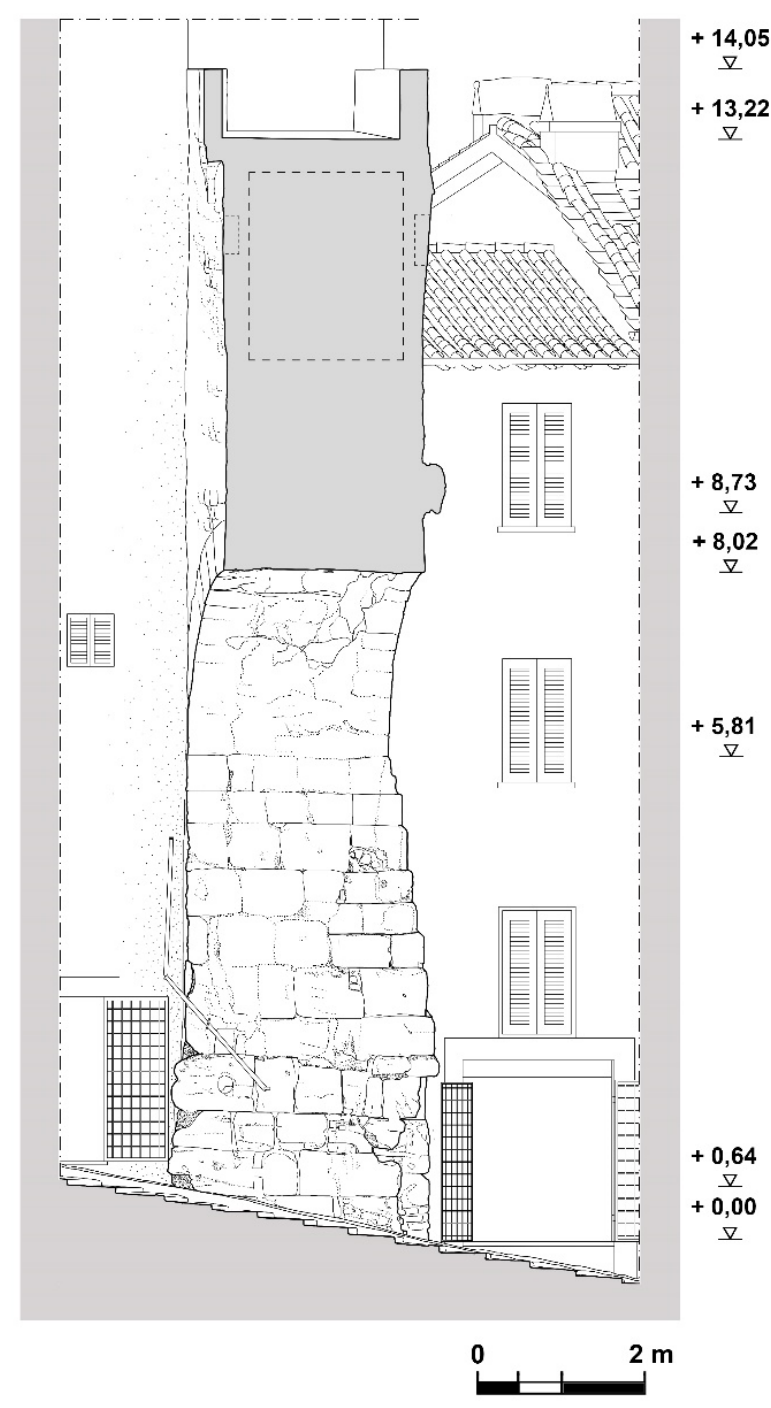

Figure 7: Section of Porta Cornea, with highlighted the retaining wall profile of one side (right).

The medieval reconstruction is evident from the springer of the doorway arch, with the Florentine arch flanked and surmounted by rows of limestone ashlars much smaller than the Etruscan ones.

On the inner side of the gate, at the still visible medieval arch shutter, you can appreciate the refined solution of keeping the vertical plane of the arch front backward from the abutment below. Thus, the wall above the arch assumes a recessed position with respect to the edge of the wall which probably corresponded to the Etruscan facing.

A brick crowing is superimposed on Porta Cornea, dating back to the period after the medieval reconstruction, of a residential character, with which a volume and a terrace were created at the top (Fig. 9).

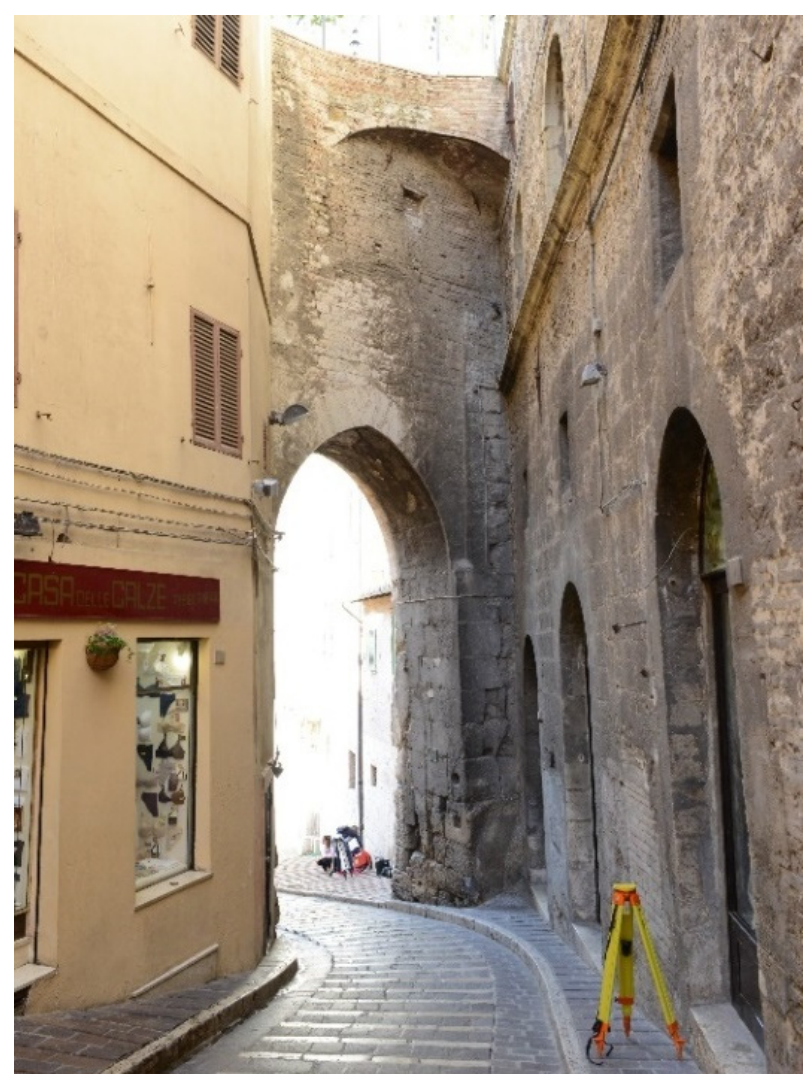

Figure 8: Internal side of Porta Cornea.

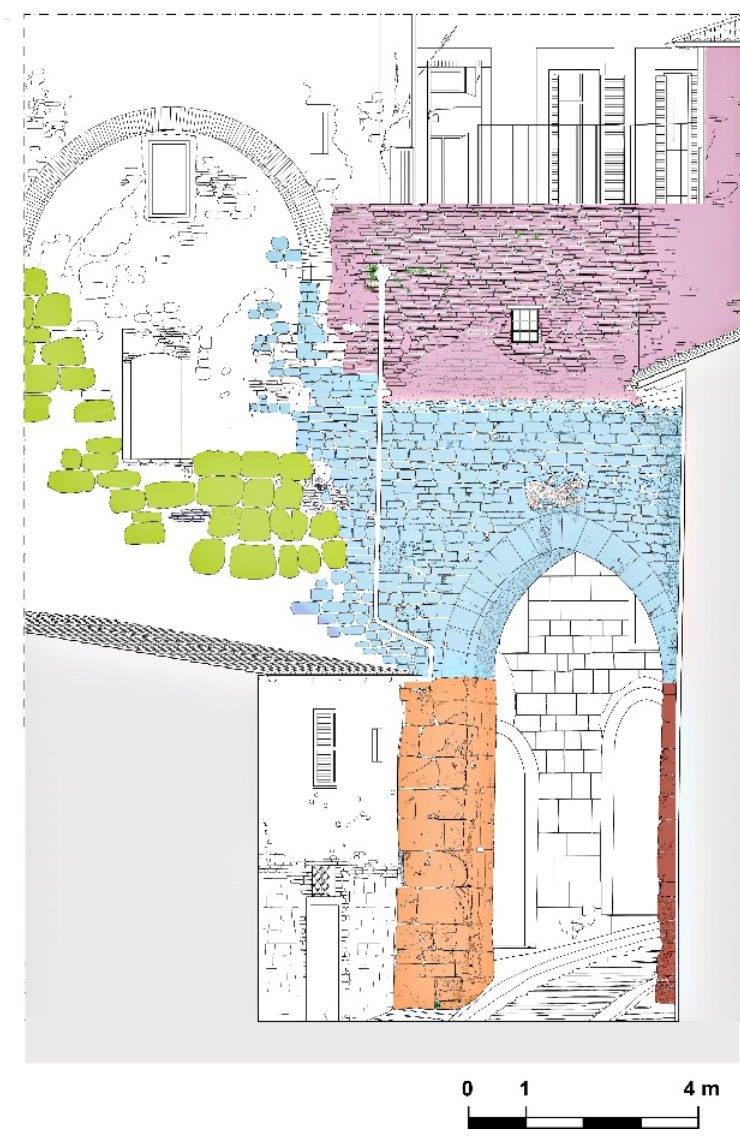

Figure 9: External front of the gate: the remains of the Etruscan walls (green) rise almost to pass Porta Cornea, divided into three materials zones, travertine (orange and red), limestone (blue), brick (purple), introduced in different periods. 


\subsection{Porta Trasimena}

It is also known as Porta di S. Luca and Madonna della Luce due to its proximity to the churches of the same name, or Porta della Luna having a half moon carved above the arch (Gigliarelli, 2016). It is oriented in the direction of Lake Trasimeno from which it takes its name (Marcaccioli, 2015).

On the external side, an abutment of the gate is flanked on one side by an extended stretch of the Etruscan walls (Fig. 10), while near the other abutment the visible portion of the walls is limited by the presence of the service areas of the Madonna della Luce church. The internal side of the gate is limited only to the vaulted passage, closed between the residential buildings and a side of the Madonna della Luce church.

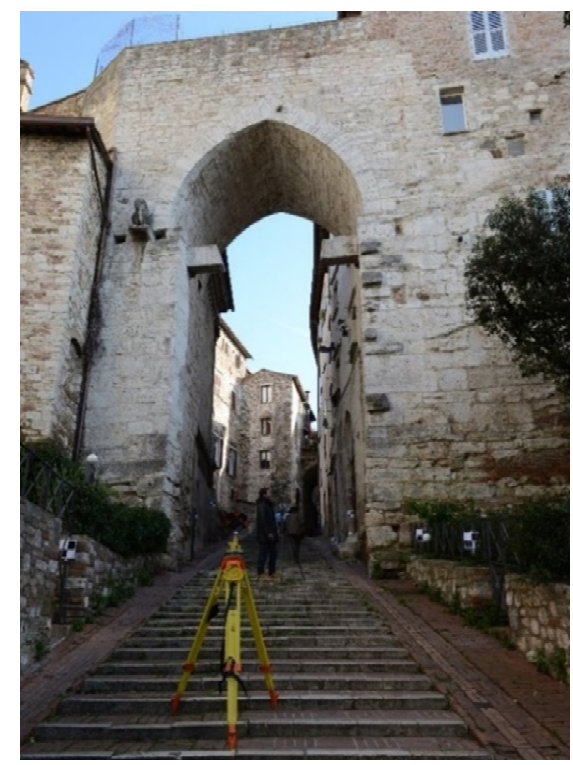

Figure 10: Porta Trasimena, external side.

Porta Trasimena highlight even more complex interpretative problems than Porta Eburnea and Porta Cornea, where the masonry facing differentiation of the successive transformation phases are more evident.

In order to formulate a proposal to differentiate the original Etruscan construction from the medieval contribution, it is useful to focus on some aspects. The first one concerns the arch with the surrounding masonry, all elements to be considered from the medieval phase, which, compared to the underlying abutment, form a wall slightly set backward, creating a recess. An additional fact to underline is that the internal sides of the gate opening have, in the lower part, brick refacing and a generally rather confused masonry (Fig. 11).

In this regard, the external jambs of the gate, which protrude from the internal sides of the passage, are instead characterized by a homogeneous masonry up to the floor. Still speaking of these jambs, it should be added that the overhanging stone corbels are inserted into them, creating a flat lintel with the central piece missing.

Next to the lintel there are stone hook hinges (completely similar to those of the Porta Eburnea) and below, at a higher level of 'via dei Priori' , a masonry connected to the jambst one was created: the stone hinge and the underlying support made up the anchoring and rotation system for the wooden shutter of the gate (Fig. 12). Furthermore, of the two external jambs, one is characterized by singular ashlars.

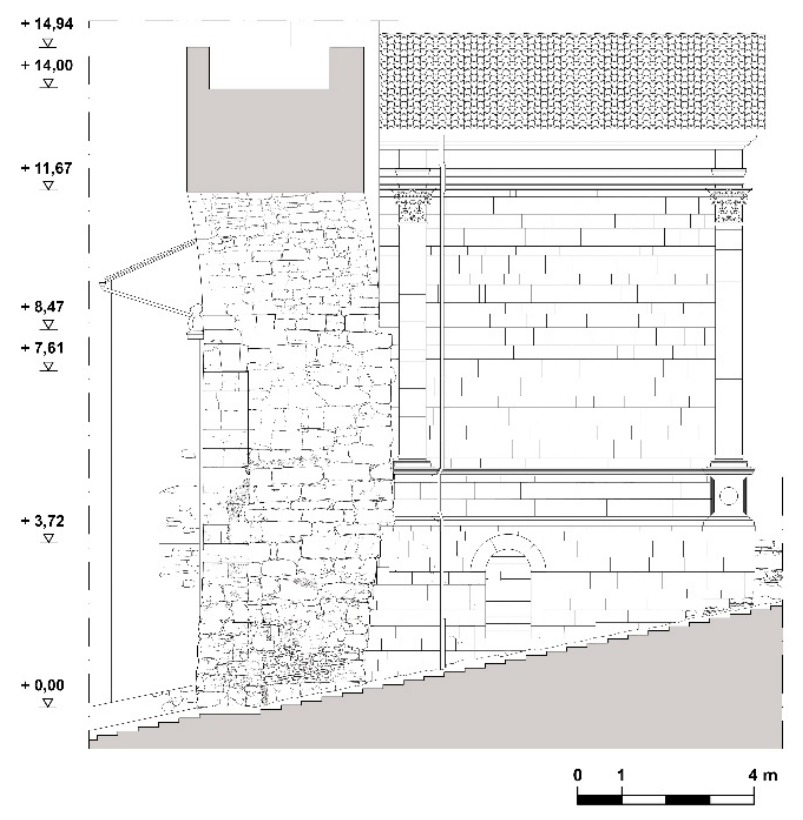

Figure 11: Section of the gate with the side of the Madonna dei Lumi church.

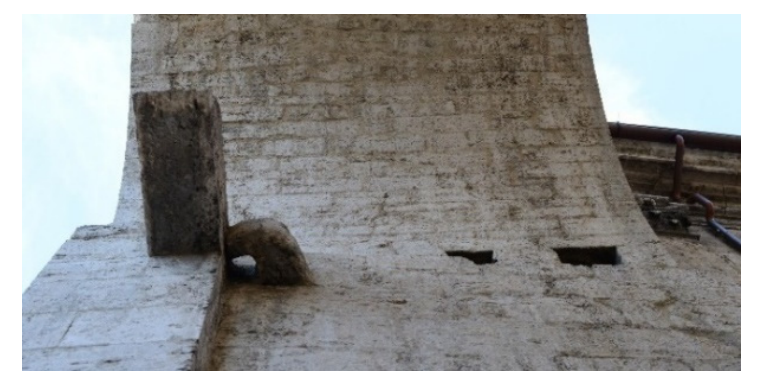

Figure 12: Detail of the stone corbel, belonging to a lintel, and of a stone hinge.

The totality of these evidences supports the hypothesis that the overall structure of the abutments of the gate is the Etruscan one and that in medieval times the gate was rebuilt from the arch springer, adding the jambs of the external side with the stone lintel and hinge system. The highest part of the shoulders shows ashlars with an excellent state of conservation; this also seems to support the contribution of restoration interventions.

A further element that could support this interpretation on the Etruscan remains is given by the greater width of the gate, equal to about $4.80 \mathrm{~m}$, compared to Porta Eburnea and Porta Cornea. At the springer level of the barrel vault of the gateway, an overturned ashlar can be seen with engraved letters that are not easily readable, but they would seem an "ER" preceded by a part of the "P"; in this case it could be an erratic ashlar that was part of the writing "AUGUSTA PERUSIA".

The sections of the Etruscan walls near the gate have been the object of extensive dismantlement works over time. The plan shows that some parts of the Madonna della Luce church, such as the main altar, a spiral staircase and part of the service areas, were created right on the wall layout, dismantling them almost completely. On 
the opposite side, inside a small opening adjacent to the stone corbel, a brick infill was found which supports demolition interventions similar to those carried out during the construction of the church (Fig. 13).

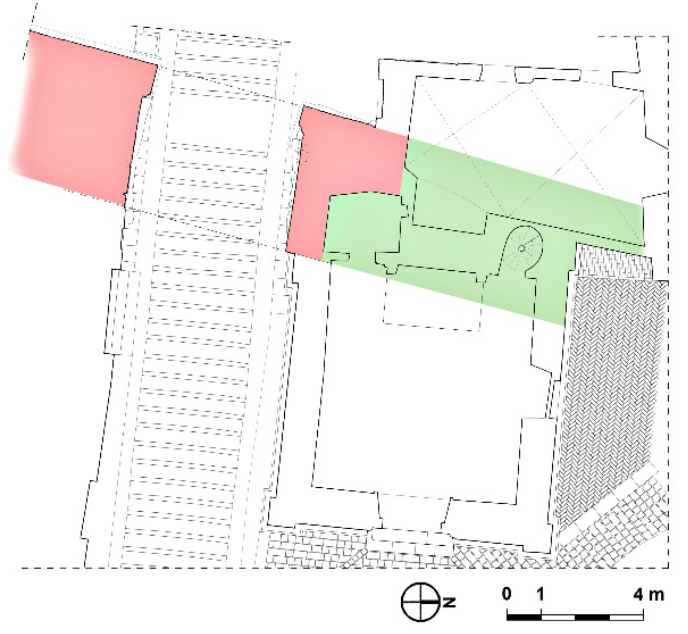

Figure 13: Plan of the gate and the adjacent Madonna dei Lumi church with highlighted the section of walls almost completely dismantled (green) to build the church.

A strong reduction in the passageway width of the medieval structure of the gate was also implemented. It was a passage created between the jambs and outlined by an entrance arch with a subsequent section of barrel vault. On one side of the gate, halfway up the jambs, the springer ashlar of this arch survives and, still above, the chiselling of some ashlars where it continued. Next to the springer ashlar there is a metal hinge and a further hinge lower; on the adjacent wall, a horizontal chiselling section indicates the springer of a barrel vault (Fig. 14).

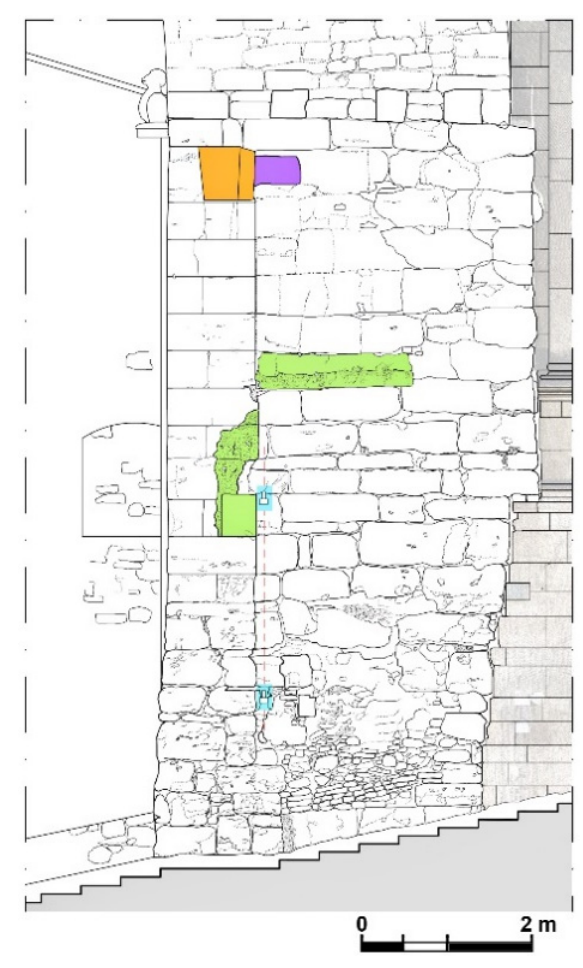

Figure 14: Detail of the gate section with the stone corbel and hinge (respectively in orange and purple), the arch springer and a barrel vault section springer (in green) of a passage much smaller than the current one.
On the other side of the gate there are no such traces; it could be supposed that they have been deleted by restorations, but it seems more likely that, in addition to reducing the height of the medieval gate, its width was also reduced by infilling it for a stretch on the edge of the reduced passageway.

\section{Survey and modelling tools and methodologies}

The development of modern innovative techniques allows a more efficient integration of Geomatics with restoration activities, creating a common and shared language useful in the cultural heritage interest (Radicioni, Stoppini, Tosi, \& Marconi, 2020; Hassani, 2015; Hoffmeister et al., 2014; Petrelli et al., 2013).

$3 \mathrm{D}$ models created by laser scanning or photogrammetry permit to carry out detailed investigations supporting the sustainable preservation and documentation of historical buildings for restoration purposes, in addition to metrical and structural studies (Balletti, Bertellini, Gottardi, \& Guerra, 2019; Matracchi, Radicioni, Stoppini, \& Tosi, 2019; Bernat, Janowski, Rzepa, Sobieraj, \& Szulwic, 2014; Armesto-González, Riveiro-Rodríguez, GonzálezAguilera, \& Rivas-Brea, 2010). All data acquired can be stored in digital databases easily available for further analysis, and can be used to create virtual spaces contributing to cultural divulgation and awareness extending them to wider audiences (Scandurra et al., 2018; Napolitano, Douglas, Garlock, \& Glisic 2017; Núñez, Buill, Regot, \& de Mesa, 2012).

In order to carry out a centimetre accuracy 3D survey of the three Perugia city gates for restoration analysis and graphic representation, some of the most advanced and efficient geomatics techniques and instruments were utilised, as briefly mentioned in the introduction:

- $\quad$ GNSS positioning;

- Optical - electronic total station;

- Terrestrial Laser Scanning laser (TLS);

- Digital Photogrammetry with cameras mounted on high tripods and telescopic bars.

Such techniques complement with each other creating an integrated survey system that led to a complete and detailed 3D geometric description of three Etruscan Perugia gates.

\subsection{GNSS positioning}

The survey had two distinct purposes:

a) accurate geometric description of each civic gate and adjacent buildings in a local coordinate system: thus, a local network was realised for each gate and measured with a total station (see next paragraph);

b) georeferencing of all civic gates in a unique global datum: for such purpose, the GNSS technique was used, in the ETRF2000 datum officially adopted by the Italian state.

Topcon Legacy GGD-E geodetic receivers with LegAnt antennas and Topcon GR-5 receivers (Fig. 15) were utilised for the survey, acquiring GPS and GLONASS 
signals in all available frequencies and modulations. More GNSS methodologies were used:

- $\quad$ post-processed static relative positioning;

- real-time kinematic survey in two modalities: RTK base-rover and Network RTK (NRTK).
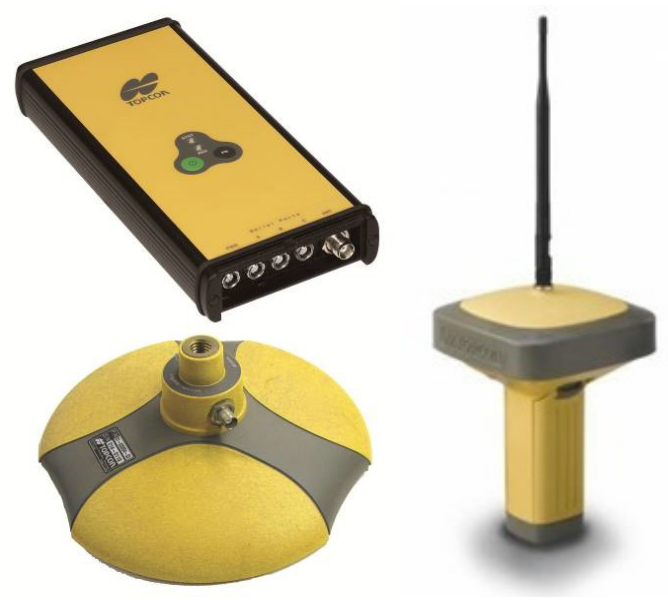

Figure 15: Topcon Legacy GNSS receiver with external LegAnt antenna (left) and Topcon GR-5 receiver with internal antenna (right).

The results are characterized by a planimetric-altimetric accuracy of about $1-2 \mathrm{~cm}$ in the absolute coordinates.

For the purpose of global datum georeferencing, the measurements connect the local network points with GNSS vertices known in the ETRF2000 system. Some permanent stations of the GPSUMBRIA GNSS network (developed since 2005 by Perugia University and Umbria Region - see Radicioni, \& Stoppini, 2019) were selected as reference points.

The local points were materialized by means of topographic nails or permanent signals on the floor, providing a geometric reference for the subsequent surveys with a minimum environmental impact.

\subsection{Total Station}

The GNSS technique, depending on satellites visibility, provides optimal results in open spaces without obstructions and obstacles such as buildings, protruding roofs and balconies, arcades and other planimetric discontinuities (Cina, 2014). In this case, as satellite visibility is limited by the gates themselves and by the other buildings facing the street, a Leica TS06 opticalelectronic total station (accuracy of about 2" on angles and $2 \mathrm{~mm}$ on distances) was used to create local reference networks (one for each surveyed gate).

Thanks to two laser pointers (one for marker centering and another for collimation purpose) and a diagonal eyepiece the TS06 permits to carry out the survey in poorly lit environments such as the inside spaces of the gates; the laser pointer also allow to perform collimations with great inclination from a lower position on considerable height buildings or manufacts. The accuracy of these local networks on vertices and targets has been estimated at about $1 \mathrm{~cm}$ for planimetry and height in the local coordinate systems.
Through the total station, the framing networks were also connected to the external points measured with the GNSS technique to the vertices and targets placed inside or near the city gates (Fig. 16).

After data processing, all points measured by total station resulted georeferenced in two ways:

a) in the local coordinate system (one for each gate);

b) in the global ETRF2000 datum.
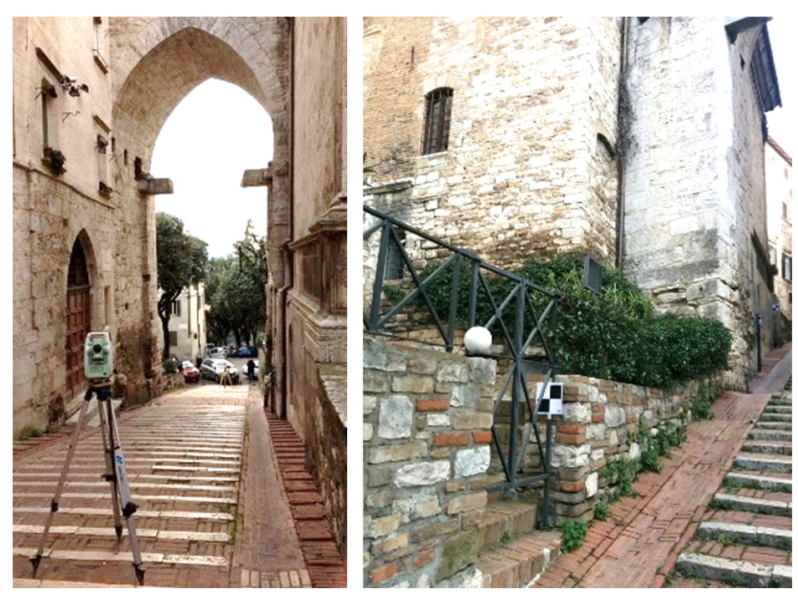

Figure 16: Total station survey, with checkerboard targets and reference spheres on the left.

\subsection{Terrestrial Laser Scanning (TLS)}

LIDAR (also referable with the acronym TLS) is one of the most powerful 3D survey tools in Geomatics. Unlike the total station, which allows to detect a limited number of points in time, the laser scanner measures a large quantity of distances and angles in very short times, thus performing a three-dimensional scan of objects, terrain and architectural artifacts (Wei, Chin, Majid, \& Setan, 2010; Abmayr, Härtl, Reinköster, \& Fröhlich, 2005).

For the city gates survey a FARO FOCUS 3D X130 laser scanner was employed, whose main feature is a speed acquisition up to 976,000 points/second. It is a very fast and accurate "phase measurement" laser scanner, particularly suitable for surveying architectures from relatively short distances and in particular for internal spaces, thanks to its small size and weight. The scans have been taken with an acquisition time of about $5-10$ minutes each (depending on distance and resolution), setting a resolution between scanned points of $10-15 \mathrm{~mm}$ at $10 \mathrm{~m}$ (Fig. 17).

After a scan is completed, the scanner also shots a $360^{\circ}$ digital photo series over the entire scanned area, thanks to an integrated coaxial 70 MPixel digital camera. This allows to obtain the so called "coloured point clouds" where the brightness and colour information of the digital images is associated to the geometric data, obtaining a realistic visualization of the scan.

Each scan produces a point cloud, consisting in an extremely high number of 3D points whose geometry refers to the instrument center (Fig. 18).

The single point clouds were acquired so that each one partially covers $40-50 \%$ of the adjacent scans, and were aligned and merged each other during processing by carrying out a relative orientation. For this purpose, two 
types of recognizable markers were used, both identifiable with great accuracy by the scanner:

- $\quad$ checkerboard pattern square plate targets;

- $\quad$ calibrated spheres with a diameter of about 15 $\mathrm{cm}$, made of synthetic resin.

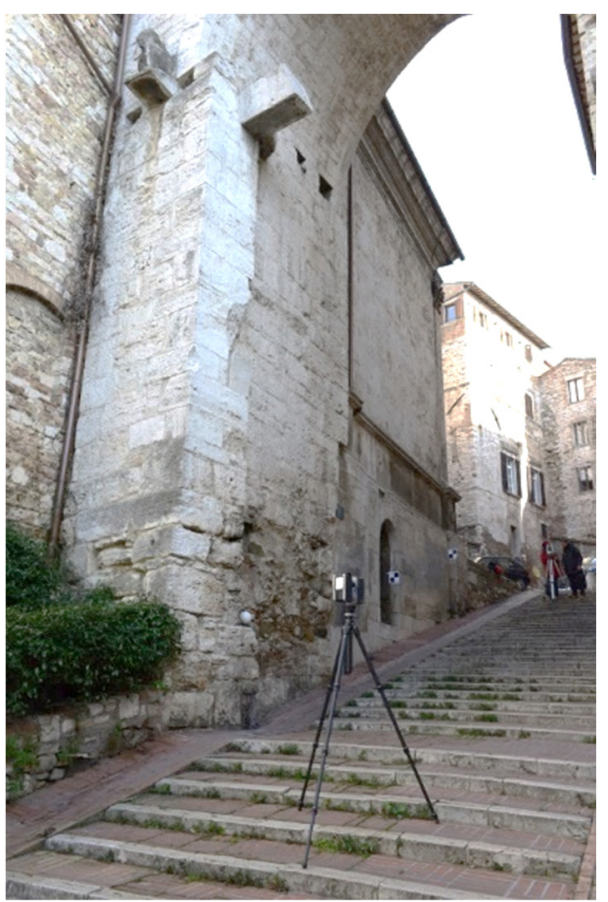

Figure 17: TLS survey.

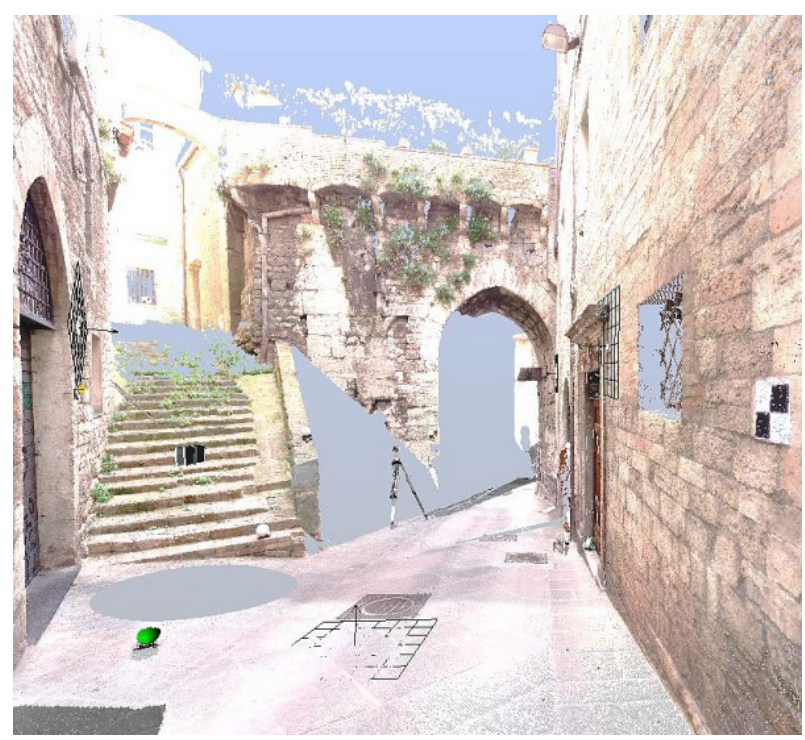

Figure 18: Coloured point cloud derived by a single scan

The processing software identifies both of them and determines their center coordinates. An adequate common number of targets (at least 4) and spheres between adjacent scans are required for a good point cloud alignment.

The advantage of the spheres with respect to the targets is that their geometry and center are absolutely defined from each position. In this way during the processing, the relative alignment point cloud error is reduced.
The relative orientation of the scans is followed by an absolute orientation (overall georeferencing of the assembled point cloud). This orientation is possible thanks to the checkerboard pattern targets, whose coordinates had been previously determined by means of total station measurements.

Given the two distinct georeference modes of the framing networks (local and global), the point cloud coordinates were also determined in the local coordinate systems of each gate and in the global ETRF2000 datum.

\section{Survey results and products}

The CAM2 Scene software (Faro CAM2, 2020) was used for processing and managing the FARO point clouds. This software performs a spatial rototranslation of the scans. Through the roto-translation algorithms the scans are aligned with each other, thus the final result is a unique point cloud georeferenced in a local system (that of a single scan assumed as reference).

"Normalized tension" is the parameter which statistically evaluates the success of the registration. In our project, the "normal tension" parameter corresponds to the "point distance", that represents the mean value of reference points residuals (Faro CAM2, 2020). A normal tension of about $2 \mathrm{~mm}$ has been obtained.

The next step is the application of a filtering to reduce the point cloud noise and an editing/cleaning process to remove all unnecessary data such double points, vegetation etc.

The models were successively processed through Leica Cyclone software (Leica Geosystems, 2020) for a registration of the point clouds on the target coordinates previously measured. At the end of the process, the residuals on known points show an average value of about $1 \mathrm{~cm}$.

The final result of the TLS survey for each gate is an overall coloured point cloud (Fig. 19), composed of millions of points, describing the three-dimensional geometry of the gate and surrounding buildings.

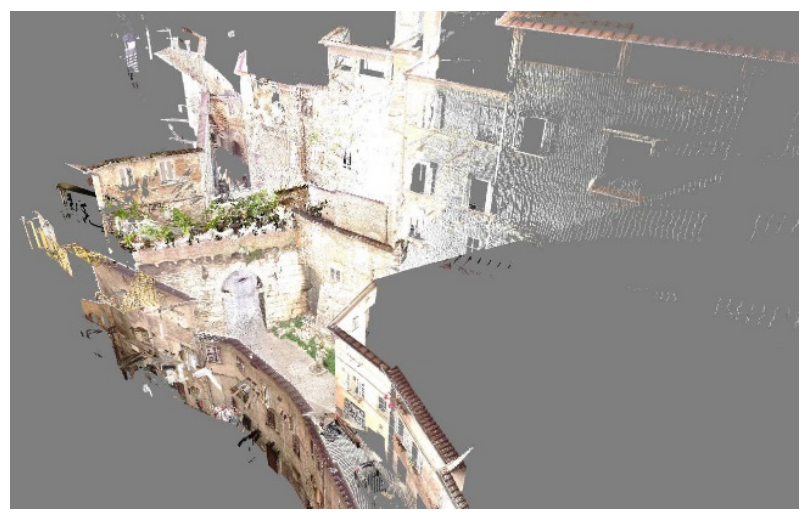

Figure 19: Assembled point cloud.

The overall point clouds for each gate (with colours and textures acquired from the digital images) were subsequently exported in the digital format JSV. These files can be distributed and viewed through the free Leica Jetstream Viewer software. With this software it is possible to measure distances, areas, volumes directly on 
the model and perform detailed analyses on a video terminal.

\section{Digital Photogrammetry}

In addition to the TLS survey, a detailed threedimensional modelling for Porta Eburnea and Porta Trasimena has been also obtained from high-resolution digital images. The photogrammetric models allow to integrate the laser scanner information especially for the unreachable or shaded areas not directly scanned by the instrument (Yastikli, 2007; Alshawabkeh, \& Haala, 2004; Kadobayashi, Kochi, Otani, \& Furukawa, 2004).

The digital images were obtained with the following photographic equipment:

- a Nikon D800E camera (36 megapixels fullframe reflex digital camera equipped with a $24 \times 36 \mathrm{~mm}$ sensor), using Nikon lenses with a fixed focal length of $14 \mathrm{~mm}, 28 \mathrm{~mm}, 50 \mathrm{~mm}$ and $85 \mathrm{~mm}$;

- a Panasonic Lumix DMC-GH4 EG-K camera (16 Megapixel mirrorless digital camera with $4 / 3$ sensor), smaller in size and weight than the previous one, with a compact and lightweight 14 $\mathrm{mm}$ focal lens (wide angle).

Both cameras were used freehand or mounted on a tripod, depending on the shutter speed.

To survey the upper parts of the manufacts, a $10 \mathrm{~m}$ carbon fiber telescopic rod with a DJI OSMO+ digital camera was used in order to shoot from a high position (Fig. 20). The DJI OSMO+ camera, very light and adjustable by means of a built-in gimbal, is remotely controlled using an Android device thanks to a support application. It represents a good solution for shooting from a high position, performing results similar to a UAV but avoiding the associated risk and authorization needs, difficult to obtain in historical centers, on artifacts limited by the Superintendence of Cultural Heritage opinion (Fig. 21).

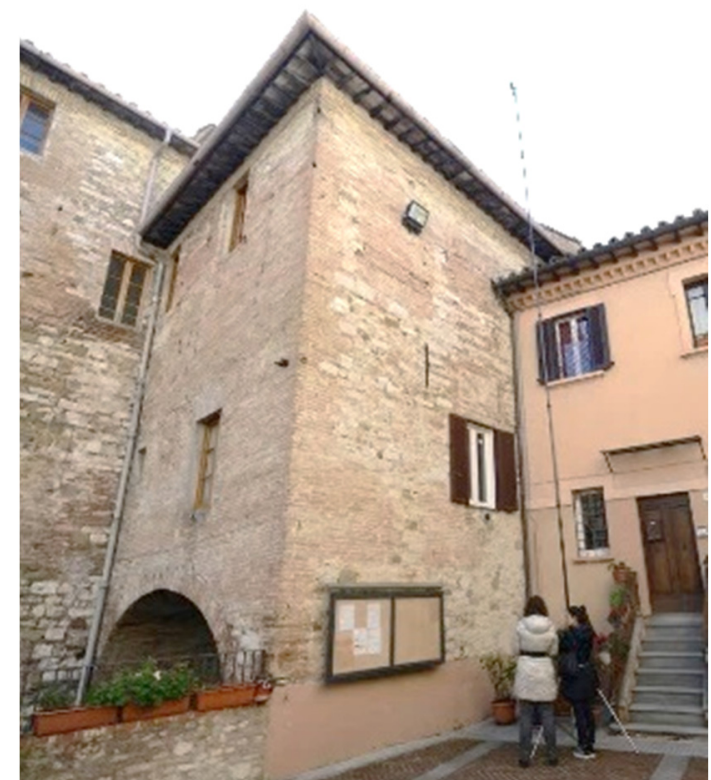

Figure 20: DJI OSMO+ digital camera mounted on a telescopic rod.

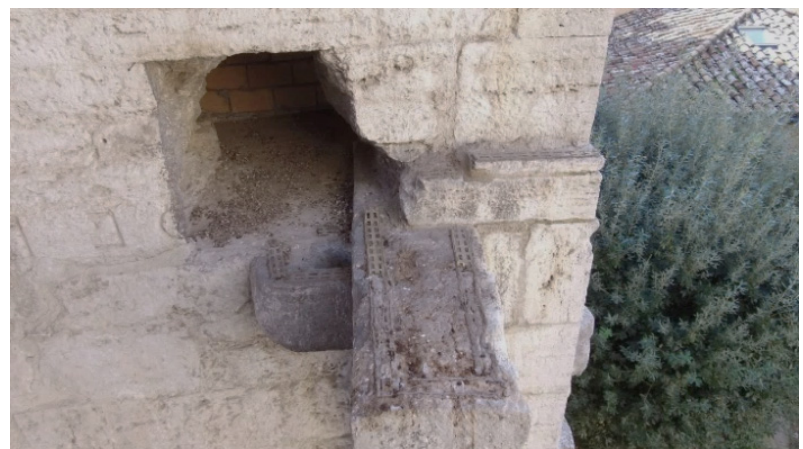

Figure 21: Particular of Porta Trasimena shot with DJI OSMO+ camera from telescopic rod.

The photogrammetric processing of the high-resolution digital images was performed by Agisoft Photoscan Professional software version 1.4.5, which uses imagebased modelling and SfM (Structure from Motion) techniques, producing 3D point cloud similar to laser scanning one (Tucci, Bonora, Conti, \& Fiorini, 2017; Kwiatek, \& Tokarczyk, 2015; Remondino, 2011).

After aligning the hundred photos taken with the two cameras and inserting the markers previously surveyed with total station and GNSS positioning, dense point clouds were obtained, consisting of million points (Fig. 22).

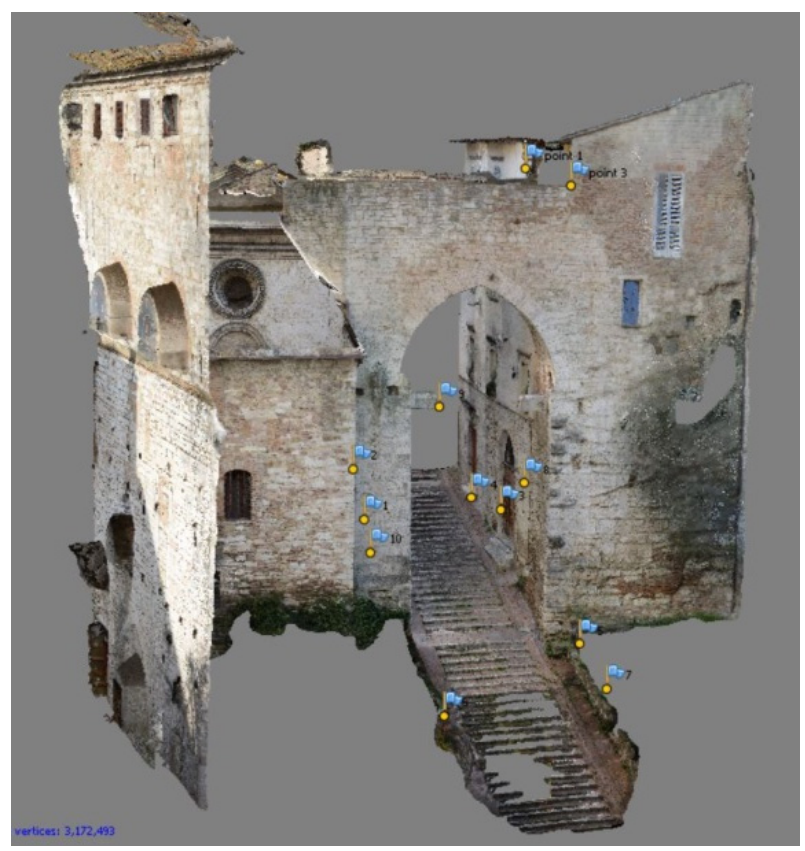

Figure 22: Porta Trasimena point cloud with markers made with Agisoft Photoscan software.

From the georeferencing, a total error of about 0.5 pixels was obtained, equal to about $5-10 \mathrm{~cm}$ in relation to distance. Thanks to the presence of the targets it was possible to use the photogrammetric point clouds to integrate the models obtained by the laser, in particular for those areas where the instrument was not able to correctly detect the points (high areas, blind spots).

From these clouds, high-definition textured mesh models were obtained (Fig. 23), from which the ortho-images were exported for material and degradation surface analysis. 


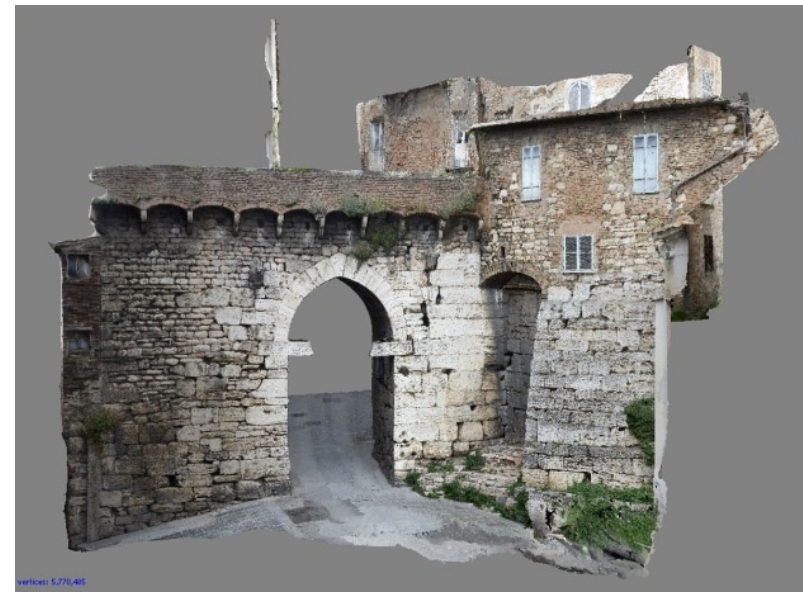

Figure 23: Porta Eburnea texturized mesh.

\section{Graphic representation and material/surface analysis}

From the 3D models, using the solution georeferenced in the local coordinate system of each gate, a series of detailed CAD vectorial drawings have been obtained, consisting of plans, sections and elevations of all the city gates surveyed.

Orthoimage files in .tif format were exported from Cyclone software, by choosing appropriate cutting planes so that it's possible to obtain sections of the $3 D$ model. CAD drawings are more traditional elaborates with respect to 3D modelling, and result easier to use in technical field without the need of special software for 3D models viewing. The advantage of these graphic data is that it's possible to print scaled drawings, which increases their accessibility even in other fields (e.g. humanities) not equipped with software which often require high hardware requirements (Fig. 24).

From the high detailed 3D model, additional 2D vectorial drawings were obtained in order to highlight the materials that characterize monuments surfaces and their state of preservation. From the graphic drawings (but also directly from the RGB point clouds) it is possible to acquire information about the state of preservation and vulnerability of the structures, crack patterns if present, and singularities of the original construction or induced by modification over time.

\section{Conclusions}

The deep transformations of the Perugia Etruscan gates leave us great importance evidence of such architecture. On Porta Eburnea and Porta Cornea, an abutment with original walls has survived which in the case of the first rise above the springer of the medieval arch, leaving an extended trace of the intrados of the original Etruscan arch. In Porta Cornea it is possible perhaps to identify the remains of three ashlars starting from the springer. If this interpretation were confirmed by further investigations, taking into account the position of the remaining arch and of the original abutment on the opposite side, we could identify the width of the original passageway, which would have had a span of about $4.30 \mathrm{~m}$, that is a dimension close to that of Porta Trasimena, where both abutments are from the Etruscan age.

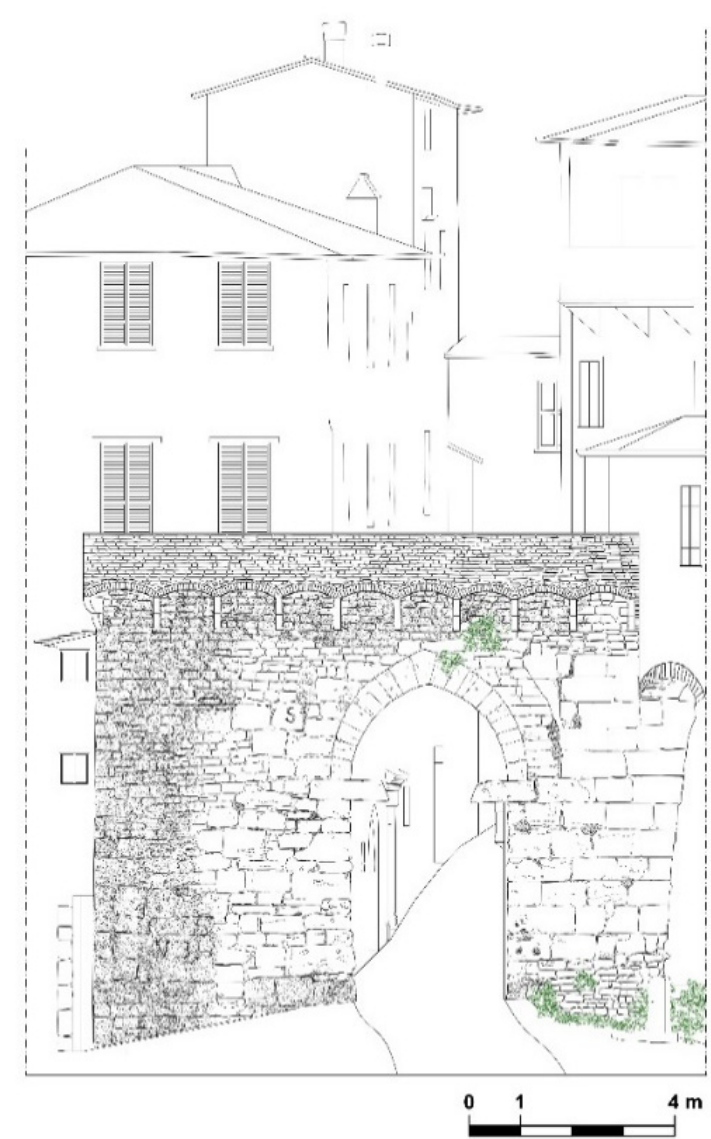

Figure 24: Example of CAD drawing (vertical section) obtained by a scan cutting plane.

The remains allow us to verify the thickness of the Etruscan walls near the gates. Those of Porta Eburnea and Porta Cornea are similar, respectively of $2.80 \mathrm{~m}$ and $2.60 \mathrm{~m}$, while the one in Porta Trasimena of $4.20 \mathrm{~m}$ is much more conspicuous. Where it is possible to check at least part of the plan of the abutments, as in Porta Eburnea and Porta Trasimena, the perpendicularity between internal facings of the gates and external facings is verified.

The most refined Etruscan masonry structures are found in Porta Eburnea and Porta Cornea where there are rows with ashlars up to $61 \mathrm{~cm}$ high, laid with thin joints. The construction technique is particularly refined in the wall sections where vertical joints orthogonal to the row are alternated with inclined vertical joints; in this way greater cohesion was ensured between adjacent ashlars of the same row, creating a jack arch between the ashlars.

A further relevant aspect is the reuse of Etruscan remains in medieval times. It is plausible that the Etruscan gates were in a state of ruin, not only due to the very long period of abandon following the loss of their military function, but also following a progressive dismantlement activity for the reuse of building material. In other words, the walls were probably considered as a kind of "quarry" from which to extract precious material, as it was already worked and available directly in the city.

The reuse of material was particularly extended in Porta Eburnea and Porta Cornea. In the first it includes ashlars with engraved letters related to the inscription "COLONIA VIBIA" and "AUGUSTA PERUSIA"; also, in Porta 
Trasimena some letters engraved in a stone may have been part of the inscription "COLONIA VIBIA". The latter is believed to have been commissioned by the Roman emperor Vibio Treboniano Gallo, originated of Perugia. The inscription "AUGUSTA PERUSIA" may have been engraved after Octavian Augustus conquered the city in 41-40 B.C. (Gigliarelli, 2016). Today these epigraphs can be read entirely in Porta Marzia and in the most famous Arco Etrusco (Cenciaioli, Mariani, \& Timpani, 2019; Di Massimo, 2019).

The use of ashlars with engraved letters would suggest to be, rather than elements left abandoned for centuries at the edge of the city gates, like stone materials available after the complete dismantlement of the Etruscan gates, in this case Porta Eburnea and Porta Trasimena, which probably occurred in medieval times. At the same time, the pointed barrel vaults were built, ended laterally by Florentine arches, which made the three gates examined in this contribution uniform.

It should be note that the medieval walls, much larger than the Etruscan one, except for a short stretch where they coincide, gave the rebuilt Etruscan gates a non-prominent defence role, at most a second defence of the most central city core. But the hypothesis that the reconstruction of the Etruscan gates wanted mainly to demonstrate how ancient the origins of the city of Perugia were can also be taken into consideration. Moreover, the closing system with wooden doors rotating on stone hinges leaning on three-pieces stone jack arches does not seem to have a military connotation that made it difficult to assault.
Today the three gates wall faces are not very visible in some parts due to the surfaces blackening, which would require further specific laboratory diagnostic investigations in order to develop the correct cleaning and conservation works.

However, the wall structures analysed through advanced survey techniques have allowed to highlight the complex urban history of Perugia still witnessed by these architectural constructions, despite having been largely incorporated by the expansion of the residential building, and are still today diminished by the lack of attention towards their high cultural significance.

The advanced techniques of Geomatics adopted for this survey (GNSS, Total Station, LIDAR and Digital Photogrammetry), effectively integrated with each other, have been confirmed as a fundamental tool for the threedimensional reconstruction at a high level of detail of cultural heritage, providing a complete and accurate documentation which constituted a solid support for the analyses performed on the ancient artefacts described in this article. The documentation acquired is however available for further studies and future developments.

\section{Acknowledgements}

This work was supported by the Cassa di Risparmio di Perugia Foundation under Grant number 2015.021.0311.

A special thanks goes to the graduate Giulia Anastasi who processed the data from the 3D model acquired by laser scanner survey, with the coordination of the authors, in order to process vectorial plants, sections and elevations represented in this article.

\section{References}

Abmayr, T., Härtl, F., Reinköster, M., \& Fröhlich, C. (2005). Terrestrial laser scanning - Applications in cultural heritage conservation and civil engineering. Proceedings of the ISPRS Working Group V/4, XXXVI-5/W17. 3D-ARCH 2005: Virtual Reconstruction and Visualization of Complex Architectures, 22-24 August, 2005, Mestre-Venice, Italy.

Alshawabkeh, Y., \& Haala, N. (2004). Integration of digital photogrammetry and laser scanning for heritage documentation. International Archives of Photogrammetry, Remote Sensing and Spatial Information Sciences, 35-B5, 424-429.

Amorini, E. (1996). Le mura etrusche della città di Perugia: percorso-guida lungo la cinta della città vecchia. Perugia, IT: Benucci.

Núñez, A., Buill, F., Regot, J., \& de Mesa A. (2012). Generation of virtual models of cultural heritage. Journal of Cultural Heritage, 13(1), 103-106. https://doi.org/10.1016/j.culher.2011.06.004

Armesto-González, J., Riveiro-Rodríguez, B., González-Aguilera, D., \& Rivas-Brea, M. T. (2010). Terrestrial laser scanning intensity data applied to damage detection for historical buildings. Journal of Archaeological Science, 37(12), 30373047. https://doi.org/10.1016/j.jas.2010.06.031

Balletti, C., Costa, M., Guerra, F., Martinello, F., \& Vernier, P. (2018). Modern and contemporary Cultural Heritage documentation and knowledge by surveying and its representation. The International Archives of the Photogrammetry, Remote Sensing and Spatial Information Sciences, XLII-2, 63-67. ISPRS TC II Mid-term Symposium "Towards Photogrammetry 2020", 4-7 June 2018, Riva del Garda, Italy. https://doi.org/10.5194/isprsarchives-XLII-2-63-2018

Balletti, C., Bertellini, B., Gottardi, C., \& Guerra, F. (2019). Geomatics techniques for the enhancement and preservation of Cultural Heritage. The International Archives of the Photogrammetry, Remote Sensing and Spatial Information Sciences, XLII-2/W11, 133-140. GEORES 2019 - 2nd International Conference of Geomatics and Restoration, 810 May 2019, Milan, Italy. https://doi.org/10.5194/isprs-archives-XLII-2-W11-133-2019

Begni Perina, G. (1956). La datazione delle antiche mura di Perugia. In Atti della Accademia di San Luca, N.S. 2.1953/56 (pp. 99-101). Roma, IT.

Bernat, M., Janowski, A., Rzepa, S., Sobieraj, A., \& Szulwic, J. (2014). Studies on the use of terrestrial laser scanning in the maintenance of buildings belonging to the cultural heritage. SGEM2014 Conference Proceedings, 2(3), 307-318. 
14th International Multidisciplinary Scientific GeoConference SGEM 2014, June 19-25, 2014, Albena, Bulgaria. https://doi.org/10.5593/SGEM2014/B23/S10.039

Bilancia, M. (2015). II muro nascosto: alla scoperta delle mura antiche di Perugia nel decennale della prima pubblicazione. Perugia, IT: Francesco Tozzuolo editore. ISBN: 978-88-95229-53-9

Calderoni, A. (1977). Evoluzione del Centro di Perugia dal periodo etrusco ad oggi. Marcaccioli E. (Ed).

Cenciaioli, L., Mariani, M., \& Timpani, M. C. (Eds.). (2019). L'Arco Etrusco di Perugia: storia e restauro. Perugia, IT: Volumnia Editrice. ISBN: 9788889024928

Cina, A. (2014). Dal GPS al GNSS (Global Navigation Satellite System). Per la geomatica. Torino, IT: Celid.

Cotana, F. (2012). L'imperatore Gaio Vibio Treboniano Gallo. Da Monte Vibiano. Perugia, IT: Morlacchi Editore. ISBN: 9788860745729

Defosse, P. (1980). Les remparts de Pérouse : contribution à l'histoire de l'urbanisme préromain. Mélanges de l'École française de Rome. Antiquité MEFRA, 92(2), 725-820. https://doi.org/10.3406/mefr.1980.1256

Di Massimo, G. (2019). Elenco delle specie vegetali presenti sulle mura dell'Arco Etrusco. In L. Cenciaioli, M. Mariani, \& M. C. Timpani (Eds.), L'Arco Etrusco di Perugia: storia e restauro (pp. 275-277).

Faro CAM2. (2020). Scene software. Retrieved March 15, 2021, from https://insights.faro.com/scene/techsheet-faro-scene and https://faro.app.box.com/s/7v2xdi8j6id4wf9g5jlledha18s9506b/file/601434891703

Fiocca, L. (1918). Le porte etrusche in Perugia. Perugia, IT: Unione Tipografica Cooperativa.

Fiocca, L. (1926). Perugia, sua origine. Cinta delle Mura e Porte. Perugia, IT: Tipografia Guerriero Guerra Editrice.

Giambi, A. (2004). Metodologie innovative per l'archeometria del travertino utilizzato nella costruzione delle "mura etrusche" di Perugia. Dissertation, supervisor Prof. Poli Giampiero, University of Perugia, Department of Physics and Geology.

Gigliarelli, R. (2016). Perugia antica e Perugia moderna. Indicazioni storico topografiche. Perugia, IT: Francesco Tozzuolo editore.

Grussenmeyer, P., Landes, T., Voegtle, T., \& Ringle, K. (2008). Comparison methods of terrestrial laser scanning, photogrammetry and tacheometry data for recording of cultural heritage buildings. The International Archives of the Photogrammetry, Remote Sensing and Spatial Information Sciences, XXXVII-B5, 213-218.

Hassani, F. (2015). Documentation of cultural heritage techniques, potentials and constraints. The International Archives of the Photogrammetry, Remote Sensing and Spatial Information Sciences, XL-5/W7, 207-214. 25th International CIPA Symposium 2015, 31 August - 04 September 2015, Taipei, Taiwan. https://doi.org/10.5194/isprsarchives-XL5-W7-207-2015

Hatzopoulos, J. N., Stefanakis, D., Georgopoulos, A., Tapinaki, S., Pantelis, V., \& Liritzis, I. (2017). Use of various surveying technologies to 3D digital mapping and modelling of cultural heritage structures for maintenance and restoration purposes: the Tholos in Delphi, Greece. Mediterranean Archaeology \& Archaeometry, 17(3), 311-336. https://doi.org/10.5281/zenodo.1048937

Hoffmeister, D., Zellmann, S., Kindermann, K., Pastoors, A., Lang, U., Bubenzer, O., Weniger, G., \& Bareth, G. (2014). Geoarchaeological site documentation and analysis of 3D data derived by terrestrial laser scanning. ISPRS Annals of the Photogrammetry, Remote Sensing and Spatial Information Sciences, II-5, 173-179. ISPRS Technical Commission V Symposium, 23-25 June 2014, Riva del Garda, Italy. https://doi.org/10.5194/isprsannals-II-5-1732014

Kadobayashi, R., Kochi, N., Otani, H., \& Furukawa, R. (2004). Comparison and evaluation of laser scanning and photogrammetry and their combined use for digital recording of Cultural Heritage. The International Archives of Photogrammetry, Remote Sensing and Spatial Information Sciences, 35(5), 401-406. XX ISPRS Congress, 12-23 July 2004 , Istanbul, Turkey.

Kwiatek, K., \& Tokarczyk, R. (2015). Immersive Photogrammetry in 3D Modelling. Geomatics and Environmental Engineering, 9(2), 51-62. https://doi.org/10.7494/geom.2015.9.2.51

Leica Geosystems. (2020). Cyclone software. Retrieved March 15, 2021, from https://leica-geosystems.com/enin/products/laser-scanners/software/leica-cyclone.

Marcaccioli, E. (2014). Porta Eburnea. Caserta e le fonti di Veggio. Perugia, IT: Futura.

Marcaccioli, E. (2015). I/ «Palmo». Visioni della terra vecchia. Perugia, IT: Futura.

Matracchi, P., Radicioni, F., Stoppini, A., \& Tosi, G. (2019). The Cathedral of s. Lorenzo in Perugia and the hypogeal spaces. Geomatic techniques for spatial investigations aimed at the knowledge and interpretation of the origin of the transept. The International Archives of the Photogrammetry, Remote Sensing and Spatial Information Sciences, XLII-2/W11, 849-856. GEORES 2019 - 2nd International Conference of Geomatics and Restoration, 8-10 May 2019, Milan, Italy. https://doi.org/10.5194/isprs-archives-XLII-2-W11-849-2019 
Napolitano, R. K., Douglas, I. P., Garlock, M. E., \& Glisic, B. (2017). Virtual Tour Environment of Cuba's National School of Art, The International Archives of the Photogrammetry, Remote Sensing and Spatial Information Sciences, XLII2/W5, 547-551. 26th International CIPA Symposium, 28 August-01 September 2017, Ottawa, Canada. https://doi.org/10.5194/isprs-archives-XLII-2-W5-547-2017

Nicolini, U. (1986). Reformationes Comunis Perusii quae extant anni MCCLXII. Deputazione di Storia Patria per I'Umbria. Fonti per la storia dell'Umbria, 5, Città di Castello, Perugia, Italy.

Petrelli, D., Ciolfi, L., Van Dick, D., Horneker, E., Not, E., \& Schmidt, A. (2013). Integrating material and digital: a new way for cultural heritage. Interactions, 20(4), 58-63. https://doi.org/10.1145/2486227.2486239

Radicioni, F., Matracchi, P., Brigante, R., Brozzi, A., Cecconi, M., Stoppini, A., \& Tosi, G. (2017). The Tempio della Consolazione in Todi: integrated geomatic techniques for a monument description including structural damage evolution in time. The International Archives of the Photogrammetry, Remote Sensing and Spatial Information Sciences, XLII-5/W1, 433-440. GEOMATICS \& RESTORATION - Conservation of Cultural Heritage in the Digital Era, 22-24 May 2017, Florence, Italy. https://doi.org/10.5194/isprs-archives-XLII-5-W1-433-2017

Radicioni, F., \& Stoppini, A. (2019). Umbria's new multi-constellation GNSS network. GEOmedia, 23(4), 6-11.

Radicioni, F., Stoppini, A., Tosi G., \& Marconi L. (2020). Necropolis of Palazzone in Perugia: integrated geomatic techniques for a geomorphological analysis. In M. Alvioli, I. Marchesini, L. Melelli \& P. Guth (Eds.), Proceedings of the Geomorphometry 2020 Conference, CNR Edizioni, Perugia, Italy. https://doi.org/10.30437/GEOMORPHOMETRY2020_18

Remondino, F. (2011). Heritage recording and 3D modeling with photogrammetry and 3D scanning. Remote sensing, 3(6), 1104-1138. https://doi.org/10.3390/rs3061104

Scandurra, S., Pulcrano, M., Cirillo, V., Campi, M., di Luggo, A., \& Zerlenga, O. (2018). Integrated survey procedures for the virtual reading and fruition of historical buildings. The International Archives of the Photogrammetry, Remote Sensing and Spatial Information Sciences, XLII-2, 1037-1044. ISPRS TC II Mid-term Symposium "Towards Photogrammetry 2020", 4-7 June 2018, Riva del Garda, Italy. https://doi.org/10.5194/isprs-archives-XLII-2-10372018

Tucci, G., Bonora, V., Fiorini, L., \& Conti, A. (2016). The Florence Baptistery: 3-D survey as a knowledge tool for historical and structural investigations. The International Archives of the Photogrammetry, Remote Sensing and Spatial Information Sciences, XLI-B5, 977-984. XXIII ISPRS Congress, 12-19 July 2016, Prague, Czech Republic. https://doi.org/10.5194/isprs-archives-XLI-B5-977-2016

Tucci, G., Bonora, V., Conti, A., \& Fiorini, L. (2017). High-quality 3D models and their use in a Cultural Heritage conservation project. The International Archives of the Photogrammetry, Remote Sensing and Spatial Information Sciences, XLII-2/W5, 687-693. 26th International CIPA Symposium, 28 August-01 September 2017, Ottawa, Canada. https://doi.org/10.5194/isprs-archives-XLII-2-W5-687-2017

Wei, O. C., Chin, C. S., Majid, Z., \& Setan, H. (2010). 3D documentation and preservation of historical monument using terrestrial laser scanning. Geoinformation Science Journal, 10(1), 73-90.

Yastikli, N. (2007). Documentation of cultural heritage using digital photogrammetry and laser scanning. Journal of Cultural heritage, 8(4), 423-427. https://doi.org/10.1016/j.culher.2007.06.003 